\title{
Öğretmen Adaylarının Akademik Öz-Yeterlikleri ve Matematik Öğretimine Yönelik Öz-Yeterliklerinin Bazı Değişkenler Açısından İncelenmesi
}

\author{
Kürşat YENILIMEZ ${ }^{1}$ \\ ${ }^{1}$ Prof. Dr. Eskişehir Osmangazi Üniversitesi Eğitim Fakültesi, kyenilmez@,ogu.edu.tr
}

Geliş Tarihi/Received: 25.4.2016 Kabul Tarihi/Accepted: 4.11.2016 e-Yayım/e-Printed: 3.1.2017

DOI: http://dx.doi.org/10.14582/DUZGEF.746

Öz

$\mathrm{Bu}$ araştırmanın amacı, öğretmen adaylarının akademik öz-yeterlikleri ile matematik öğretimine yönelik özyeterliklerinin bazı değişkenler açısından incelenmesidir. Araştırmada ilişkisel tarama modeli kullanılmıştır. Araştırmanın katılımcılarını bir devlet üniversitesinde Eğitim Fakültesi Okul Öncesi, Sınıf ve İlköğretim Matematik Öğretmenliği programında öğrenim gören 3. sınıf öğrencileri arasından gönüllülük esasına göre seçilen 188 öğretmen adayı oluşturmaktadır. Araştırmanın verileri "Akademik Öz-yeterlik Ölçeği” ve "Matematik Öğretimine Yönelik Öz-yeterlik Ölçeği” ile toplanmıştır. Verilerin analizinde betimsel istatistik, t-testi ve tek yönlü varyans analizinden yararlanılmıştır. Araştırma sonucunda; öğretmen adaylarının akademik öz-yeterliklerinin ve matematik öğretimine yönelik öz-yeterliklerinin genel olarak “orta” düzeyde olduğu, sınıf öğretmeni adaylarının akademik özyeterliklerinin okul öncesi öğretmeni adaylarına göre daha yüksek olduğu, akademik başarısı yüksek olan öğretmen adaylarının akademik öz-yeterliklerinin ve matematik öğretimine yönelik öz-yeterliklerinin de daha yüksek olduğu, ilköğretim matematik ve sınıf öğretmeni adaylarının matematik öğretimine yönelik öz-yeterliklerinin okul öncesi öğretmeni adaylarına göre daha yüksek olduğu ve öğretmen adaylarının akademik öz-yeterlik ve matematik öğretimine yönelik öz-yeterlikleri arasında pozitif anlamlı orta düzeyde bir ilişki olduğu belirlenmiştir.

Anahtar Kelimeler: akademik öz-yeterlik, matematik öğretimine yönelik öz-yeterlik, öğretmen aday1

\section{Examination of Prospective Teachers' Academic Self-efficacy and Self- efficacy toward Teaching Mathematics in terms of Some Variables}

\begin{abstract}
The purpose of this study was to examine prospective teachers' academic self-efficacy and self-efficacy toward teaching mathematics in terms of some variables. Relational survey method was used in the study. The participants were $1883^{\text {rd }}$ grade prospective teachers from Preschool Education, Elementary Education and Middle School Mathematics Education departments in a government university. These prospective teachers were selected from the volunteers. In order to obtain data, "Academic Self-efficacy Scale" and "Self-efficacy toward Teaching Mathematics Scale" were used. Descriptive statistics, t-test and one way ANOVA were used for the analysis of the data. Results showed that, prospective teachers' academic self-efficacy and self-efficacy toward teaching mathematics were generally "middle" level. According to the results of the study; prospective elementary education teachers have higher academic self-efficacy than prospective preschool education teachers, prospective teachers who have high academic success have higher academic self-efficacy and self-efficacy toward teaching mathematics, prospective middle school mathematics teachers and prospective elementary school teachers have higher self-efficacy toward teaching mathematics than prospective preschool education teachers and positive significant relation between prospective teachers' academic self-efficacy and self-efficacy toward teaching mathematics.
\end{abstract}

Keywords: academic self-efficacy, self-efficacy toward teaching mathematics, prospective teacher 


\section{GİRİŞ}

Yeterlik kavramı "bir işi yapma gücünü sağlayan özel bilgi, görevini yerine getirme gücü” olarak tanımlanmaktadır (Türk Dil Kurumu [TDK], 2005). Öz-yeterlik kavramı ise Bandura (1997) tarafindan "bireyin belirli bir performansı gösterebilmek için gereken etkinlikleri başarma kapasitesi hakkında kendine yönelik yargısı" olarak tanımlanmıştır. Öz-yeterlik, Bandura’nın Sosyal Öğrenme Teorisi’nin birçok araştırmaya konu olan anahtar kavramlarından birisidir. Bireyin öz-yeterliğini geçmiş performanslar, modeller, sosyal/sözel övgüler/iknalar, psikolojik durumlar gibi faktörlerin etkilediği ileri sürülmektedir (Wood \& Bandura, 1989; Bandura, 2000). Akademik öz-yeterlik ise, bireyin akademik bir işi başarı ile tamamlayabilme konusundaki kendine ilişkin inancıdır. Bireylerin yüksek akademik öz-yeterliğe sahip olmalarının önemli olduğunu gösteren birçok çalışma yapılmıştır. Özellikle öğrencilerin akademik özyeterliklerinin akademik başarıyı artırdığı pek çok araştırmada tespit edilmiştir (Bandura, 1997; Pajares, 1997 akt. Yllmaz, Gürçay \& Ekici, 2007). Bandura (1997), akademik öz-yeterliği "bireyin akademik bir konu alanında başarılı olabileceğine ilişkin inancı" olarak tanımlamaktadır. Zimmerman (1995) ise akademik öz-yeterliğin temel özelliklerini şöyle sıralamaktadır: 1) Öz-yeterlik bireylerin fiziksel ya da psikolojik özelliklerini değil, belirli bir işi gerçekleştirme yeteneği konusundaki yargılarını içermektedir. 2) Öz-yeterlik inancı, çok boyutlu olup farklı alanlarla bağlantılıdır. 3) Öz-yeterlik, duruma bağlı bir özellik sergiler. 4) Öz-yeterlik, performans için belirlenen ölçütler temel alınarak ölçülür (Bıkmaz, 2004'den akt. Öncü, 2012).

Öz-yeterliğin bireyin davranışlarının önemli bir yordayıcısı olduğu düşünülmektedir (Schunk, 1991). Bu nedenle "meslek öz-yeterliğ’” olarak da adlandırılabilen bireyin sahip olduğu mesleği en iyi şekilde icra etme konusundaki öz-yeterliğinin belirlenmesi önemli bir araştırma konusudur. Meslek öz-yeterliği konusundaki araştırmalara en çok konu olan mesleklerden birisi de öğretmenliktir. Bu bağlamda öğretmen öz-yeterliği “öğretmenin, öğrencinin performansını etkileme kapasitesi ve görevini başarıyla yerine getirebilmek için gerekli davranışlan gösterip gösteremeyeceğine ilişkin inancı" olarak tanımlanmaktadır (Ashton, 1984 akt. Ekici, 2006). Öz-yeterliği düşük olan bir öğretmenin öğrencilerine, meslektaşlarına ve topluma güven vermesi ve onlardan gerekli itibarı görmesi oldukça güçtür. Şüphesiz bu sorumluluk ve baskıy1 en yoğun biçimde üzerinde hissedenlerden biri de matematik öğretmenleridir. İlkokuldan üniversiteye kadar tüm öğretim kademelerinde öğrencilerine gerekli matematik bilgi ve kültürünü kazandırmaya çalş̧an ve böylece onlara yaşamları boyunca karşılaşacakları problemlerin üstesinden gelebilecek matematiksel donanımı sağlamaya çalışan matematik öğretmenlerinin önemli bir sorumluluk üstlendikleri söylenebilir. Nitekim matematik dersi öğretim programında dile getirilen matematik öğretmenlerinin sahip olması gereken özelliklerden birisi de matematiği öğretme konusunda kendini yeterli bulma ve özgüven duyma şeklindedir (Milli Eğitim Bakanlı̆̆1 [MEB], 2008). Bu bağlamda öğretmenlerin matematik öğretimi konusunda öz-yeterliklerinin yüksek olması beklenmektedir.

Matematik eğitimi okul öncesi dönemden üniversiteye kadar zorunlu eğitimin tüm kademelerinde yer almaktadır. Matematik dersi ile çocuk okul öncesi dönemde ilk matematiksel kavramları geliştirmekte, ilkokulda somut düşünme ve ortaokulda ise soyut düşünme becerisi elde etmektedir. Söz konusu dönemlerde matematik derslerini yürütecek öğretmen adaylarının matematik öğretimi konusunda kendilerini ne kadar yeterli hissettiklerinin bir göstergesi olarak matematik öğretimine yönelik öz- 
yeterliklerinin incelenmesi önemli bir araştırma konusu olarak görülmektedir. Böylece söz konusu özyeterliğin düşük olması durumunda hizmet öncesi dönemde gerekli önlemler alınabilecek ve göreve başladıktan sonra matematik öğretimi konusunda özgüven sorunu yaşanmayacaktır.

Alanyazında bireylerin mesleki öz-yeterliklerinin çeşitli değişkenler açısından incelendiği bazı araştırmalar mevcuttur. Kahyaoğlu \& Yangın (2007) tarafından ilköğretim öğretmen adaylarının mesleki öz-yeterliklerine ilişkin görüşlerinin incelenmesi amaciyla gerçekleştirilen çalsşma sonucunda, fen bilgisi ve sınıf öğretmeni adaylarının mesleki öz-yeterliklerinin ilköğretim matematik öğretmeni adaylarından daha yüksek olduğu belirlenmiştir.

Dede (2008), matematik öğretmenlerinin öğretimlerine yönelik öz-yeterlik inançlarını araştırdığ1 çalışması sonucunda hem ilköğretim ikinci kademede hem de lisede görev yapan matematik öğretmenlerinin, etkili matematik öğretimi yaptıklarına ve öğretim yeterliğine sahip olduklarına yönelik inançlarının, öğrencileri matematiğe yönelik motive etmek ve onlara yardımcı olmak noktasındaki inançlarına göre daha yüksek düzeyde olduğunu belirlemiştir. Ayrıca aynı çalışmada ilköğretim ve lisede görev yapma durumunun ölçeğin tamamı ve faktörleri bakımından anlamlı bir farklılık yaratmadığı da dile getirilmektedir.

Aksu (2008), sınıf, fen bilgisi ve okul öncesi öğretmeni adaylarının matematik öğretimine ilişkin özyeterlik inançlarını araştırdığı çalısmanın sonucunda öğretmeni adaylarının matematik öğretimine ilişkin özyeterlik inancı ve başa çıkma davranışı alt boyutları açısından yüksek eğilimlere sahip olduklarını tespit etmiştir. Ayrıca aynı çalışmada öğretmen adaylarının matematik öğretimine yönelik öz-yeterlik inançlarının cinsiyete, lisede mezun olunan alana ve branşa göre farklılık göstermediği de dile getirilmektedir.

Hacıömeroğlu \& Şahin-Taşkın (2010) tarafından sınıf öğretmeni adaylarının matematik öğretimi yeterlik inançlarının incelendiği araştırmanın sonucunda, öğretmen adaylarının matematik öğretimi yeterlik inançlarının Kişisel Yeterlik boyutunda "katılmıyorum”, Etkili Öğretimde Öğretmenin Rolü ve Öğretime İlişkin Performans boyutlarında ise "katılıyorum" aralığına karşılık geldiği tespit edilmiştir. Bunun yanında öğretmen adaylarının matematik öğretimi yeterlik inançlarının cinsiyete, başarıya ve sınıf düzeyine göre farklılık göstermediği de araştırmanın bulguları arasındadır.

Doruk \& Kaplan (2012) tarafından sınıf öğretmeni adaylarının matematik öğretimine yönelik özyeterlik inançlarının incelendiği araştırmanın sonucunda, öğretmen adaylarının matematik öğretimine yönelik öz-yeterlik inançlarının orta düzeyde olduğu tespit edilmiştir. Bunun yanında öğretmen adaylarının matematik öğretimine yönelik öz-yeterlik inançlarının cinsiyete, mezun olunan lise türüne ve sınıf düzeyine göre farklılık göstermediği de araştırmanın bulguları arasındadır.

Şahin, Gökkurt \& Soylu (2014) tarafindan öğretmenlerin ve öğretmen adaylarının matematik öğretimi öz-yeterlik inançlarının karşılaştırılması amacıyla gerçekleştirilen çalışmanın sonucunda, öğretmenlerin ve öğretmen adaylarının matematik öğretimi öz-yeterlik inançlarının yüksek düzeyde olduğu ancak gruplar arasında anlamlı bir farklılaşma olmadığı belirlenmiştir.

Peker (2016), sınıf öğretmeni adaylarının matematik öğretimi kaygısı ile matematik öğretimine yönelik öz-yeterlik inancı arasındaki ilişkiyi incelemek amacıyla gerçekleştirdiği çalısmanın sonucunda matematik öğretimi kaygı ölçeğinin İçerik Analizi boyutunun matematik öğretimine yönelik öz-yeterlik inanç ölçeğinin 
Öğretimde yeterlik, Motivasyon ve sorumluluk alma ve Etkili öğretim boyutları üzerinde negatif bir etkisinin olduğunu tespit etmiştir.

Alan yazından da görüldüğü gibi öğretmen ve öğretmen adaylarının matematik öğretimine yönelik özyeterliklerinin ne düzeyde olduğu ve bu yeterliği hangi değişkenlerin etkilediği halen üzerinde çalışılan güncel bir araştırma problemidir. Bu nedenle bu çalışmada okul öncesi, sınıf ve ilköğretim matematik öğretmeni adaylarının matematik öğretimine yönelik öz-yeterlikleri ile akademik öz-yeterliklerinin öğrenim gördükleri program ve akademik başarı değişkenleri açısından incelenmesi amaçlanmıştır. Huinker \& Madison (1997), öğretmen adaylarının matematik öğretimine yönelik inançlarının, öğretimlerine ilişkin davranışlarının şekillenmesinde etkili bir rol oynayacağını ifade etmektedir.

\section{YÖNTEM}

Çalışma ilişkisel türde bir tarama çalışmasıdır. Tarama modelleri genel olarak var olan durumu ya da gerçekliği olduğu gibi araştırıp açıklamayı amaçlamaktadır. İlişkisel tarama modeli ise genellikle birden fazla değişken arasındaki etkileşimlerin belirlenmesinde kullanılmaktadır.

\subsection{Kat1limcilar}

Bir devlet üniversitesinin Eğitim Fakültesi Okul Öncesi, Sınıf ve İlköğretim Matematik Öğretmenliği programında öğrenim gören 3. sınıf öğrencileri arasından gönüllülük esasına göre seçilen 188 öğretmen aday1 katılımcıları oluşturmaktadır. Katılımciların \%83.5’i kız, \%16.5’i erkektir; \%54.3’ü 2-2.99 arası, \%45.7'si 3-4 arası akademik başarıya sahiptir ve \%27.6's1 Okul Öncesi Öğretmenliği, \%36.2'si Sınıf Öğretmenliği, \%36.2’si İlköğretim Matematik Öğretmenliği programında öğrenim görmektedir.

\subsection{Veri Toplama Araçları}

Veri toplama araçları olarak, Dede (2008) tarafından uyarlanan "Matematik Öğretimine Yönelik Özyeterlik Ölçeğı’" ve Yılmaz ve arkadaşları (2007) tarafindan uyarlanan "Akademik Öz-yeterlik Ölçeğı" kullanılmıştır. Bu iki ölçek dışında kullanılan bilgi formunda ise öğretmen adaylarının öğrenim gördükleri lisans programını ve mevcut akademik başarı ortalamalarını ifade etmeleri istenmiştir.

\section{Matematik Ögretimine Yönelik Öz-yeterlik Ölçeği}

Matematik Öğretimine Yönelik Öz-yeterlik Ölçeği, Riggs \& Enochs (1990) tarafindan geliştirilen "Fen Öğretimi Yeterlik İnancı Ölçeğı̀”nden matematik eğitimine uyarlanmıştır. Likert tipinde 14 maddeden oluşmakta olan ölçeğin yapı geçerliği Dede (2008) tarafından sağlanmıştır. Ölçeğin geçerliğini belirlemek üzere açımlayıcı faktör analizi yapılmış ve ölçeğin "öğretimde yeterlik", "motive etme ve sorumluluk alma" ve "etkili öğretim” şeklinde üç faktöre sahip olduğu belirlenmiştir. Ölçeğin güvenirliğine ilişkin Cronbach Alpha içtutarlılık katsayısı ise .80 olarak hesaplanmıştır.

\section{Akademik Öz-yeterlik. Ölçeği}

Akademik Öz-yeterlik Ölçeği, Jerusalem \& Schwarzer (1981)'den uyarlanmış olup toplam 7 maddeden oluşmaktadır. Almanca olan orijinal ölçeğin Türkçe'ye çevirisi dil uzmanlarınca yapılmıştır. Daha sonra Türkçe'ye uygunluk, içerik ve ölçme değerlendirme yönünden ilgili uzmanlar tarafindan değerlendirilmiştir. Alınan görüşler doğrultusunda düzenlenen ölçeğin geçerlik ve güvenirliğinin saptanması amacıyla Yılmaz ve arkadaşları (2007) tarafından pilot uygulaması yapılmıştır. Yapılan faktör 
analizi sonucunda Türkçe'ye uyarlanan ölçeğin, aynen orijinalindeki gibi tek boyutlu olduğu belirlenmiştir. Ölçeğin güvenirliğine ilişkin Cronbach Alpha içtutarlılık katsayısı ise .79 olarak hesaplanmıştır.

\subsection{Veri Analizi}

Akademik Öz-yeterlik ve Matematik Öğretimine Yönelik Öz-yeterliklerin genel analizi ortalama ve standart sapma değerleri kullanılarak yapılmıştır. Akademik Öz-yeterlik ve Matematik Öğretimine Yönelik Öz-yeterliklerin akademik başarıya göre farklılaşıp farklılaşmadığı bağımsız örneklemler t-testi ile araştırılmıştır. Akademik Öz-yeterlik ve Matematik Öğretimine Yönelik Öz-yeterliklerin programa göre farklılaşıp farklılaşmadığı tek yönlü varyans analizi ile araştırılmıştır. Akademik Öz-yeterlik ve Matematik Öğretimine Yönelik Öz-yeterlik arasında ilişki olup olmadığı Pearson Korelasyon analizi ile araştırılmıştır.

\section{BULGULAR}

$\mathrm{Bu}$ bölümde araştırmanın amacına uygun olarak belirlenen bulgulara ve yorumlara yer verilmiştir. Araştırmada öncelikli olarak öğretmen adaylarının akademik öz-yeterliklerinin (AOY) genel analizi yapılmış ve sonuçlar Tablo 1'de sunulmuştur.

Tablo 1. Akademik öz-yeterliklerin genel analizi

\begin{tabular}{lllll}
\hline & Minimum & Maksimum & Ortalama & Standart Sapma \\
\hline AÖY & 11 & 34 & 24.05 & 4.04 \\
\hline
\end{tabular}

Tablo 1'e göre, öğretmen adaylarının akademik öz-yeterliklerinin düşük-orta-yüksek şeklinde bir sıralama yapıldığında "orta” düzeyde olduğu söylenebilir.

Öğretmen adaylarının akademik öz-yeterliklerinin öğrenim gördükleri programa göre farklılaşıp farklılaşmadığı tek yönlü varyans analizi ile incelenmiştir. Tespit edilen farklllıkların hangi programlar arasında olduğu ise Tukey çoklu karşılaştırma testi yardımıyla belirlenmiştir. Varyans analizi ve Tukey testi sonucunda elde edilen sonuçlar Tablo 2'de sunulmuştur.

Tablo 2. Akademik öz-yeterliklerin programa göre farklillğ

\begin{tabular}{llllllll}
\hline & Kaynak & K.T. & SD & K.O. & F & p & Fark \\
\hline AÖY & Gruplar Arası & 169.86 & 2 & 84.93 & 5.44 & .01 & SÖ-OÖ \\
& Grup İçi & 2886.71 & 185 & 15.60 & & & \\
Genel & 3056.57 & 187 & & & & \\
\hline
\end{tabular}

Tablo 2'ye göre, öğretmen adaylarının akademik öz-yeterlikleri öğrenim gördükleri programa göre anlamlı bir farklılık göstermektedir. Tukey testi sonucunda bu farklılı̆̆ın sınıf öğretmeni adaylarının akademik öz-yeterliklerinin okul öncesi öğretmeni adaylarından daha yüksek oluşundan kaynaklandığ1 anlaşılmıştır.

Öğretmen adaylarının akademik öz-yeterliklerinin akademik başarılarına göre farklılaşıp farklılaşmadı̆̆ t-testi ile incelenmiş test sonucunda elde edilen sonuçlar Tablo 3'de sunulmuştur.

Tablo 3. Akademik öz-yeterliklerin akademik başarıya göre farklılı̆̆1

\begin{tabular}{llllll}
\hline Akademik Başarı & $\mathbf{N}$ & Ortalama & Standart Sapma & $\mathbf{t}$ & $\mathbf{p}$ \\
\hline $2-2.99$ & 102 & 23.45 & 3.79 & -2.23 & .03 \\
$3-4.00$ & 86 & 24.76 & 4.23 & & \\
\hline
\end{tabular}


Tablo 3'e göre, öğretmen adaylarının akademik öz-yeterlikleri akademik başarılarına göre anlamlı bir farklılık göstermektedir. Akademik başarısı daha yüksek olan öğretmen adaylarının akademik özyeterliklerinin de daha yüksek olduğu tespit edilmiştir.

Akademik öz-yeterliğin söz konusu değişkenler açısından farklılaşma durumlarının incelenmesinin ardından öğretmen adaylarının matematik öğretimine yönelik öz-yeterliklerinin (MÖÖY) genel analizi yapılmış ve sonuçlar Tablo 4'de sunulmuştur.

Tablo 4. Matematik öğretimine yönelik öz-yeterliklerin genel analizi

\begin{tabular}{lllll}
\hline & Minimum & Maksimum & Ortalama & Standart Sapma \\
\hline MÖÖY & 34 & 62 & 48.49 & 5.81 \\
-Öğretimde yeterlik & 5 & 20 & 13.89 & 2.47 \\
-Motive etme ve sorumluluk alma & 11 & 26 & 19.16 & 2.92 \\
-Etkili öğretim & 8 & 20 & 15.44 & 2.12 \\
\hline
\end{tabular}

Tablo 4'e göre, öğretmen adaylarının matematik öğretimine yönelik öz-yeterliklerinin düşük-ortayüksek şeklinde bir sıralama yapıldığında “orta” düzeyde olduğu söylenebilir. Ölçeğin alt boyutları değerlendirildiğinde, söz konusu öz-yeterliklerin “öğretimde yeterlik (ÖY)” boyutu açısından "orta" düzeyde, "motive etme ve sorumluluk alma (MESA)" boyutu açısından "orta” düzeyde ve "etkili öğretim (EÖ)” boyutu açısından “yüksek” düzeyde olduğu söylenebilir.

Öğretmen adaylarının matematik öğretimine yönelik öz-yeterliklerinin öğrenim gördükleri programa göre farklılaşıp farklılaşmadığı tek yönlü varyans analizi ile incelenmiştir. Tespit edilen farklılıkların hangi programlar arasında olduğu ise Tukey çoklu karşılaştırma testi yardımıyla belirlenmiştir. Varyans analizi ve Tukey testi sonucunda elde edilen sonuçlar Tablo 5'de sunulmuştur.

Tablo 5'e göre, öğretmen adaylarının matematik öğretimine yönelik öz-yeterlikleri öğrenim gördükleri programa göre anlamlı bir farklılık göstermektedir. Tukey testi sonucunda bu farklılı̆̆ın sınıf öğretmeni ve ilköğretim matematik öğretmeni adaylarının matematik öğretimine yönelik öz-yeterliklerinin okul öncesi öğretmeni adaylarından daha yüksek oluşundan kaynaklandığ1 anlaşılmıştır. Ölçeğin alt boyutları değerlendirildiğinde, "öğretimde yeterlik" ve "motive etme ve sorumluluk alma” boyutları açısından sınıf öğretmeni adaylarının matematik öğretimine yönelik öz-yeterliklerinin okul öncesi öğretmeni adaylarından daha yüksek olduğu, “etkili öğretim” boyutu açısından ise hem sınıf öğretmeni hem de ilköğretim matematik öğretmeni adaylarının matematik öğretimine yönelik öz-yeterliklerinin okul öncesi öğretmeni adaylarından daha yüksek olduğu söylenebilir. 
Tablo 5. Matematik öğretimine yönelik öz-yeterliklerin programa göre farklılığ1

\begin{tabular}{llllllll}
\hline & Kaynak & K.T. & SD & K.O. & F & p & Fark \\
\hline MÖÖY & Gruplar Aras1 & 496.46 & 2 & 248.23 & 7.90 & .00 & İMÖ-OÖ \\
& Grup İçi & 5814.52 & 185 & 31.43 & & & SÖ-OÖ \\
& Genel & 6310.98 & 187 & & & & \\
ÖY & Gruplar Aras1 & 62.79 & 2 & 31.40 & 5.39 & .01 & SÖ-OÖ \\
& Grup İçi & 1077.86 & 185 & 5.83 & & & \\
& Genel & 1140.65 & 187 & & & & \\
MESA & Gruplar Aras1 & 68.31 & 2 & 34.16 & 4.14 & .02 & SÖ-OÖ \\
& Grup İçi & 1526.90 & 185 & 8.25 & & & \\
& Genel & 1595.21 & 187 & & & & İÖ-OÖ \\
EÖ & Gruplar Arasi & 39.04 & 2 & 19.52 & 4.52 & .01 & SÖ-OÖ \\
& Grup İçi & 799.32 & 185 & 4.32 & & & \\
\hline
\end{tabular}

Öğretmen adaylarının matematik öğretimine yönelik öz-yeterliklerinin akademik başarılarına göre farklılaşıp farklılaşmadığı t-testi ile incelenmiş test sonucunda elde edilen sonuçlar Tablo 6'da sunulmuştur.

Tablo 6. Matematik öğretimine yönelik öz-yeterliklerin akademik başarıya göre farklılığ1

\begin{tabular}{lllllll}
\hline & Akademik Başar1 & $\mathbf{n}$ & Ortalama & Standart Sapma & $\mathbf{t}$ & $\mathbf{p}$ \\
\hline MÖÖ & $2-2.99$ & 102 & 47.48 & 5.79 & -2.63 & .01 \\
& $3-4.00$ & 86 & 49.69 & 5.63 & & \\
ÖY & $2-2.99$ & 102 & 13.45 & 2.48 & -2.69 & .01 \\
& $3-4.00$ & 86 & 14.41 & 2.37 & & \\
\multirow{2}{*}{ MESA } & $2-2.99$ & 102 & 18.86 & 2.94 & -1.52 & .13 \\
& $3-4.00$ & 86 & 19.51 & 2.88 & & \\
EÖ & $2-2.99$ & 102 & 15.17 & 1.91 & -1.95 & .05 \\
& $3-4.00$ & 86 & 15.77 & 2.31 & & \\
\hline
\end{tabular}

Tablo 6’ya göre, öğretmen adaylarının matematik öğretimine yönelik öz-yeterlikleri akademik başarılarına göre anlamlı bir farklılık göstermektedir. Akademik başarısı daha yüksek olan öğretmen adaylarının matematik öğretimine yönelik öz-yeterliklerinin de daha yüksek olduğu tespit edilmiştir. Ölçeğin alt boyutları değerlendirildiğinde, “öğretimde yeterlik” ve “etkili öğretim” boyutları açısından akademik başarısı daha yüksek olan öğretmen adaylarının matematik öğretimine yönelik öz-yeterliklerinin daha yüksek olduğu söylenebilir.

Öğretmen adaylarının akademik öz-yeterlikleri ile matematik öğretimine yönelik öz-yeterlikleri arasında istatistiksel olarak ilişki olup olmadığı Pearson korelasyon analizi ile incelenmiş analiz sonucunda elde edilen sonuçlar Tablo 7'de sunulmuştur.

Tablo 7. Akademik öz-yeterlik ile matematik öğretimine yönelik öz-yeterlik arasındaki ilişki

\begin{tabular}{lll}
\hline & & AÖ \\
\hline MÖÖY & $\mathrm{r}$ & .38 \\
& $\mathrm{p}$ & .00 \\
\hline
\end{tabular}

Tablo 7’ye göre, öğretmen adaylarının akademik öz-yeterlikleri ile matematik öğretimine yönelik özyeterlikleri arasında istatistiksel olarak anlamlı, pozitif, “orta” düzeyde bir ilişki olduğu söylenebilir. 


\section{TARTIŞMA ve SONUÇ}

Araştırmadan elde edilen bulgular doğrultusunda öğretmen adaylarının akademik öz-yeterliklerinin ve matematik öğretimine yönelik öz-yeterliklerinin genel olarak "orta” düzeyde olduğu sonucuna ulaşılmıştır. Bu sonuç alan yazındaki bazı çalışmaların (Hacıömeroğlu \& Şahin-Taşkın, 2010; Doruk \& Kaplan, 2012; Turğut, 2013) sonuçlarıla paralellik gösterirken, bazı çalışmaların (Yılmaz, Gürçay \& Ekici, 2007; Aksu, 2008; Oğuz, 2012; Şahin, Gökkurt \& Soylu, 2014) sonuçlarıyla farklllık göstermektedir. Bu farklllıklar söz konusu çalışmaların katılımcılarının öğrenim gördükleri bölümlerin farklı olmasından kaynaklanmış olabilir.

Araşıırma sonucunda sınıf öğretmeni adaylarının akademik öz-yeterliklerinin, okul öncesi öğretmeni adaylarına göre daha yüksek olduğu tespit edilmiştir. Nitekim Oğuz (2012) çalışmasında da sınıf öğretmeni adaylarının akademik öz-yeterlik inançlarının “yüksek” düzeyde olduğu ifade edilmektedir.

Araştırmadan elde edilen sonuçlardan birisi de ilköğretim matematik ve sınıf öğretmeni adaylarının matematik öğretimine yönelik öz-yeterliklerinin, okul öncesi öğretmeni adaylarına göre daha yüksek olduğu şeklindedir. Bu durum okul öncesi öğretmeni adaylarının öğretmenlik yapacakları yaş grubundaki çocuklara matematik bilgi ve becerilerini kazandırma konusunda bazı çekincelere sahip oldukları şeklinde yorumlanabilir. Bu sonuç alan yazındaki bazı çalışmaların sonuçları ile uyuşmamaktadır. Örneğin, Aksu (2008) ve Şahin, Gökkurt \& Soylu (2014) çalışmalarında öğretmen adaylarının matematik öğretimine yönelik öz-yeterlik inançlarının branşa göre farklılık göstermediği dile getirilmektedir.

Çalışmada ayrıca akademik başarısı yüksek olan öğretmen adaylarının akademik öz-yeterliklerinin ve matematik öğretimine yönelik öz-yeterliklerinin de daha yüksek olduğu sonucuna ulaşılmıştır. Öğretmen adaylarının akademik öz-yeterlik ve matematik öğretimine yönelik öz-yeterlikleri arasında pozitif anlamlı orta düzeyde bir ilişki olduğu da elde edilen sonuçlar arasındadır. Bu iki sonuç birbirini destekler niteliktedir.

Araştırmadan elde edilen bulgulara dayanarak aşağıdaki öneriler geliştirilmiştir:

* Öğretmen adaylarının matematik öğretimine yönelik öz-yeterliklerinin daha üst düzeylere taşınabilmesi için okullarda uygulama çalışmaları artırılabilir. İlk sınıftan itibaren Okul Deneyimi uygulamalarına yer verilebilir.

* Okul öncesi öğretmeni adaylarının matematik öğretimine yönelik öz-yeterliklerinin artırılabilmesi için üniversitelerin kreş ve anaokullarında daha çok uygulama yapma olanakları sağlanabilir.

* Öğretmen adaylarının akademik öz-yeterliklerinin daha üst düzeylere taşınabilmesi için Eğitim fakültelerinde öğrencilere sunulan akademik danışmanlık ve rehberlik hizmetleri artırilabilir.

* Benzer çalışma 4. sınıf öğretmen adayları, lise matematik öğretmen adayları ve mevcut öğretmenler üzerinde yapılarak genişletilebilir. 


\section{KAYNAKÇA}

Aksu, H. H. (2008). Öğretmen adaylarının matematik öğretimine yönelik öz-yeterlilik inançları. Abant $\dot{I}_{\text {zzet }}$ Baysal Üniversitesi Eğitim Fakültesi Dergisi, 8 (2), 161-170.

Bandura, A. (1997). Self-efficacy: The exercise of control. New York: Freeman.

Bandura, A. (2000). Cultivate self-efficacy for personel and organizational effectiveness. E. A. Locke (Eds), Handbook of principles of organization behavior (ss.120-136) içinde. Oxford: Blackwell.

Dede, Y. (2008). Matematik öğretmenlerinin öğretimlerine yönelik öz-yeterlik inançları. Türk Eğitim Bilimleri Dergisi, 6 (4), 741-757.

Doruk, M. \& Kaplan, A. (2012). Sınıf öğretmeni adaylarının matematik öğretimine yönelik öz-yeterlik inançlarının incelenmesi. The Journal of Academic Social Science Studies, 5(7), 291-302.

Ekici, G. (2006). Meslek lisesi öğretmenlerinin öğretmen öz-yeterlik inançları üzerine bir araştırma. Eğitim Arastirmalar, 8, 87-96.

Hacı̈̈meroğlu, G. \& Şahin-Taşkın, Ç. (2010). Sınıf öğretmeni adaylarının matematik öğretimi yeterlik inançları. Uludağ Üniversitesi Ĕ̈itim Fakültesi Dergisi, 23 (2), 539-555.

Huinker, D. \& Madison, S. K. (1997). Preparing efficacious elementary teachers in science and mathematics: The influence of methods courses. Journal of Science Teacher Education, 8 (2), 107-126.

Kahyaoğlu, M. \& Yangın, S. (2007). İlköğretim öğretmen adaylanının mesleki öz-yeterliklerine ilişkin görüşleri. Kastamonu Üniversitesi Kastamonu Ĕ̈itim Dergisi, 15 (1), 73-84.

MEB (2008). İlkägretim Matematik Dersi 6-8. Simflar Ögrretim Programı. Ankara: MEB Yayınlar1

Oğuz, A. (2012). Sınıf öğretmeni adaylarının akademik öz-yeterlik inançları. Anadolu Journal of Educational Sciences International, 2 (2), 15-28.

Öncü, H. (2012). Akademik öz-yeterlik ölçeği'nin Türkçe'ye uyarlanması. Abi Evran Üniversitesi Krrşehir Eğitim Fakëiltesi Dergisi, 13 (1), 183-206.

Schunk, D. H. (1991). Self-efficacy and academic motivation. Educational Psychologist, 26 (3\&4), 207-231.

Şahin, Ö., Gökkurt, B. \& Soylu, Y. (2014). Öğretmenlerin ve öğretmen adaylarının matematik öğretimi özyeterlik inançlarının karşılaştırılması. Dicle Üniversitesi Zijya Gökalp Eğitim Fakültesi Dergisi, 22, 120-133.

Turgut, M. (2013). Academic self-efficacy beliefs of undergraduate mathematics education students. Acta Didactica Napocensia, 6(1), 33-40

Türk Dil Kurumu (2005). Türkşe Söəlïk. Ankara: Türk Dil Kurumu Yayınları.

Wood, R. \& Bandura, A. (1989). Social cognitive theory of organizational management. The Academy of Management Review, 14 (3), 361-384.

Yılmaz, M., Gürçay, D. \& Ekici, G. (2007). Akademik öz-yeterlik ölçeği’nin Türkçe'ye uyarlanması. Hacettepe Üniversitesi Ë̆itim Fakültesi Dergisi, 33, 253-259.

Zimmerman, B. J. (1995). Self-efficacy and educational development. A. Bandura (Eds), Self-efficacy in changing societies (ss.202-231) içinde. New York: Cambridge University Press..

\section{Citation Information}

Yenilmez, K. (2016) Öğretmen Adaylarının Akademik Öz-Yeterlikleri ve Matematik Öğretimine Yönelik Öz-Yeterliklerinin Bazı Değişkenler Açısından İncelenmesi. Dicle Üniversitesi Ziya Gökalp Eğitim Fakülltesi Dergisi, 29, 324-332. 